\title{
Role of mobile technology in the construction industry - a case study
}

\author{
Sitalakshmi Venkatraman*
}

School of Information Technology and Mathematical Sciences

University of Ballarat

P.O. Box 663, Ballarat, Victoria 3353, Australia

E-mail: s.venkatraman@ballarat.edu.au

*Corresponding author

\section{Pak Yoong}

School of Information Management

Victoria University of Wellington

Kelburn Parade

P.O. Box 600, Wellington 6001, New Zealand

E-mail: pak.yoong@vuw.ac.nz

\begin{abstract}
The construction industry is facing a number of pressures to decrease costs, improve productivity and have a competitive edge in terms of quality of service and customer satisfaction. Recent advancements in mobile technology provide new avenues for addressing this situation. This paper presents the role of emerging mobile technologies and, in particular, the development of a mobile facsimile solution that assists collaborative communications between parties on or away from the construction site.

This paper first identifies potential use cases for mobile technologies in the construction industry and highlights the issues that would hamper their adoption. It discusses the modelling of the problems related to the workflow of a construction process with the aid of a focus group formed with various construction industry representatives in New Zealand. The various problem-solving processes adopted by the industry practitioners at different functional levels are analysed and the findings summarised. Finally, this paper describes the development of one such mobile solution, called ClikiFax, which could address some of the issues and pressures prevailing in the context of the New Zealand construction industry.
\end{abstract}

Keywords: mobile technologies; remote site; construction process; workflow; productivity.

Reference to this paper should be made as follows: Venkatraman, S. and Yoong, P. (2009) 'Role of mobile technology in the construction industry - a case study', Int. J. Business Information Systems, Vol. 4, No. 2, pp.195-209.

Biographical notes: Dr. Sitalakshmi Venkatraman is a Senior Lecturer in the School of Information Technology and Mathematical Sciences at the University of Ballarat, Australia. Prior to that she worked in the School of Information Management at Victoria University of Wellington (VUW), where she carried out this research work. Her current research interests concentrate on e-commerce and mobile computing. She has 20 years of work experience - in industry, developing turnkey projects, and in academics, teaching a variety 


\begin{abstract}
of IT courses. She has published technical research papers in internationally well-known refereed journals. She has peer-reviewed several research articles and is also a reviewer for the ACM New Zealand Chapter.

Dr. Pak Yoong is an Associate Professor of Information Systems/E-commerce at Victoria University of Wellington. Yoong teaches in the areas of virtual organisation, research methods and IS leadership. His research, teaching and consulting experience is in the facilitation of virtual meetings, online communities of practice, online knowledge sharing, mobile collaborations and human resource development in information technology environments. $\mathrm{He}$ is a coeditor and author of the book IT Human Resource Management Challenges in the Internet Age. His work has been published in such journals as Journal of Information Technology \& People, The DATABASE for Advances in Information Systems, Journal of Information and Knowledge Management, Journal of Systems and Information Technology, and Journal of Internet Research.
\end{abstract}

\title{
1 Introduction
}

The construction industry predominantly consists of a mobile workforce. This is attributed to the fact that construction activities are quite dispersed and take place at frequently changing remote site locations. According to Chan and Liu (2007), "The construction industry is complex and multidimensional." Due to the complex nature of construction projects involving physically dispersed parties such as contractors, architects, workers, suppliers and customers, there exists a need to have a collaborative communication system among these remote site parties to achieve a successful project completion (Chien et al., 2003; Vlachopoulou and Manthou, 2006; Chong et al., 2007). Hence, the construction industry experiences a need to manage remote collaborations and subsequently an increased pressure to reduce costs and improve productivity by reducing process inefficiencies (Laborde and Sanvido, 1994; Equential, 2004; Ismail et al., 2006). As Aziz et al. (2004) stated: "Collaboration needs of site based staff and other mobile workers are not well addressed." In this context, 'Mobile Technology' could play a vital role in improving the efficiency of the construction processes. Currently, as part of business communications, Information Technology (IT) solutions connecting with Telefax machines are being used extensively for exchange of information such as drawings, pictures, schedules, documents and other workflow-related information (Adriaanse et al., 2004; Momaya and Ajitabh, 2005). However, with the fast technological improvements in mobile computing, such as handheld personal computers, is the construction industry able to make an effective use of such advancements?

In general, some researchers have reported that mobile computing is yet to have a significantly positive impact on the construction industry as IT innovations have been adopted in a piecemeal fashion (Raimonda and Salvioni, 1998; Aziz et al., 2004; Motawa et al., 2004; Vlachopoulou and Manthou, 2006; Chong et al., 2007). This research paper investigates the potential use of mobile technologies within the New Zealand construction sector.

The paper first describes the background of the case study in Section 2 and the research methodology undertaken in Section 3. Section 4 discusses the findings from the initial phase of the research project by identifying the opportunities and barriers in the use 
of internet-enabled mobile devices within New Zealand's construction environment. Subsequently, it highlights the possible solutions to such issues and describes a mobile technology-based solution developed and evaluated during the implementation phase of this study. Finally, Section 5 presents the conclusions and suggestions for future research.

\section{Case study background}

It is a global fact that similar to today's transformed distributed manufacturing process, the construction process requires collaboration between many physically dispersed parties for it to be undertaken efficiently and successfully (Chien et al., 2003; Bennett and Vaidya, 2005; Chong et al., 2007; Gunasekaran and Ngai, 2007; Lee, 2007). It is necessary for construction information not only to travel to remote sites to become sharable enterprise-wide but also to get translated from the digital 'virtual' world into the material 'real' world, and vice versa (Vlachopoulou and Manthou, 2006). This could result in a loss of consistency, clarity and efficiency. Such a mixed handling of data could have a negative impact on the workflow processes (Aziz et al., 2004).

In New Zealand, modern communication technologies such as the telephone, facsimile and e-mail have enabled members within the construction workflow process to be cities or even continents apart. However, computer utilisation within the construction workflow has not been up to the full potential and has been channelled only to certain areas of design and management. This situation is similar to that of other countries where it was found that though the introduction of computers is well established in the office workflow of design information, the 'field' information still remains to be predominantly paper based (Pham and Dawson, 2003; Li et al., 2006). Mobile technologies and other digital tools have been promising to bridge this physical and information gap especially with regard to the office productivity scenarios (Alexander et al., 1998; Venkatraman, 2005). However, industry predictions are clouded by the relatively limited research undertaken into application requirements, barriers and consequent effects of these new mobile technologies within the construction workflow (Magdic et al., 2002; Chan and Liu, 2007). This warrants a research study that investigates the potential avenues of mobile communication technologies to enhance the workflow or communication efficiency of the field workforce within the construction industry.

This research study explored the potential avenues for the use of new mobile technologies within construction industry. In particular, it was aimed at proposing mobile solutions to enhance efficiency of workflow processes and to design and develop one such mobile application, which was subsequently tested and evaluated within New Zealand construction industry.

\section{Research methodology}

The methodology used for this research study was subdivided into the following three phases: (1) exploratory phase, (2) design and development phase and (3) field usability and evaluation phase. 


\subsection{Exploratory phase}

The main aim of the exploratory phase was to gain a broad understanding of the issues, problems and potential avenues for digital mobile communications to enhance workflow processes in the construction arena (Harrison et al., 2004). We adopted a two-stage data collection strategy: data from a focus group and then from individual interviews. The term focus group is defined as a group of four to ten people, moderated by a facilitator(s), that are organised to discuss a topic or set of topics of special interest to the participants (Plax and Cecchi, 1989). Yoong and Huff (2007) have found the focus group to be a useful and fast technique for gathering research data as the group participants normally have some common knowledge that relate to the topic(s) being considered.

During the early part of 2003, a group of nine participants from the building construction industry were invited to take part in a focus group. The participants included a building contractor, two architects, an interior designer, an electrician, five architecture and design lecturers and a building researcher (see Figure 1).

Figure 1 Stakeholders from the construction industry

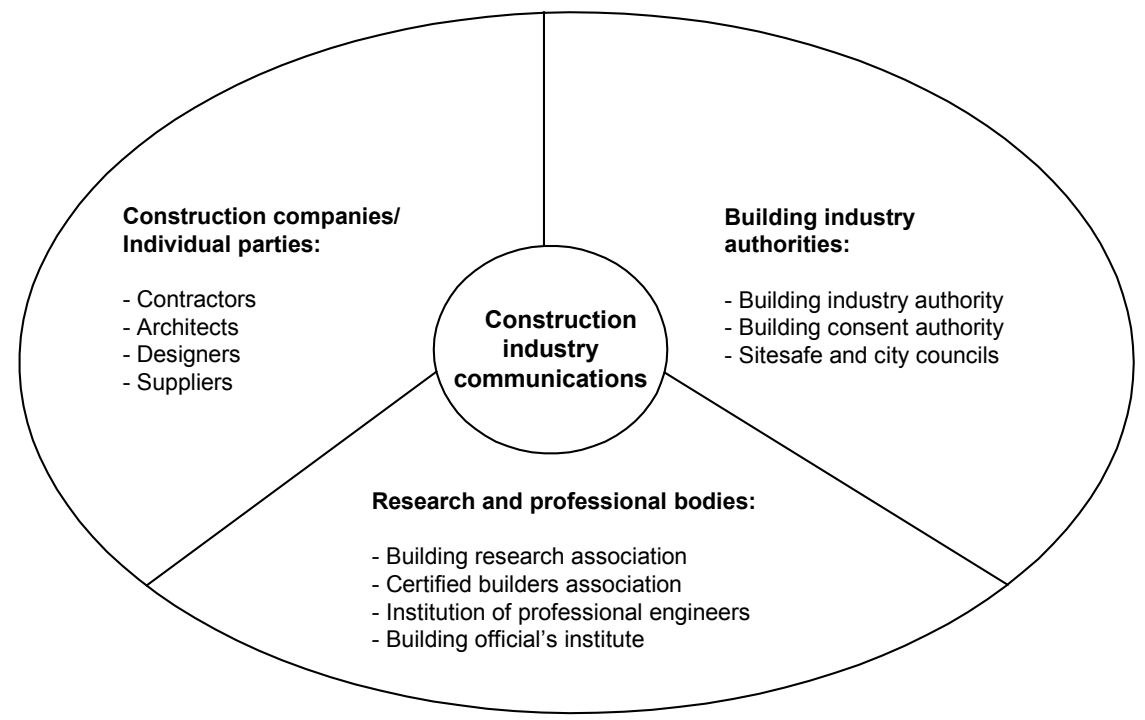

The transcripts from the focus group discussion and a summary of the main points were returned to the respective participants for checking for accuracy. All feedback comments were subsequently incorporated in the final version of the interim report.

During the second stage of the study we conducted semi-structured interviews with a number of the participants. These unstructured interviews have provided us with more in-depth data relating to some key factors that were uncovered during the focus group. The results from this phase are reported in a later section.

\subsection{Design and development phase}

The main objective of the design and development phase was to draw inputs from the exploratory phase to design and develop a prototype for a mobile solution that could aid and enhance communications anytime and anywhere in the construction industry. It was 
realised that usability perspectives were essential to be examined while designing the interfaces of the mobile solution. Hence, the design and development phase included hardware and software usability considerations for the mobile solution. An iterative prototype development approach of System Design Life Cycle (SDLC) methodology was adopted to design and develop the mobile solution (Figure 2).

Figure 2 Iterative prototype design and development

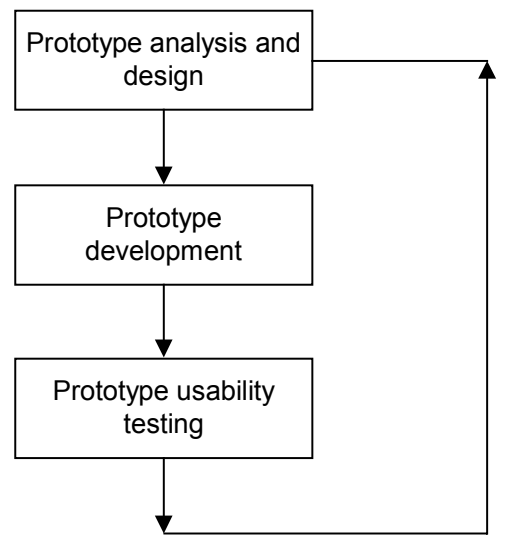

A heuristic testing of the mobile solution was conducted at each iterative cycle of the prototype development (Wright et al., 2005). This was conducted internally by software developers and designers of the mobile solution. At each stage in the iterative process of the design and development phase, the usability issues were rated and prioritised, which helped in improving the prototype of the mobile solution.

\subsection{Field usability and evaluation phase}

There could be several barriers that could hinder an IT implementation process (Nilsson, 2007). Hence, for the mobile solution, the main purpose of conducting the field usability and evaluation was to unveil the experiences obtained by companies in order to identify potential values or impacts of this mobile technology convergence in their business processes. We adopted a qualitative survey-based methodology for the field usability and evaluation phase (Venkatraman et al., 2007). The survey was based on certain existing theoretical models such as Technology Acceptance Model (TAM) (Davis, 1986) and Diffusion of Innovation Theory (DIT) (Rogers, 1995). We have focused on the following three main influencing factors that were derived from these theories:

1 task/job-related factors

2 behavioural factors

3 environmental factors.

Figure 3 provides the main activities we had identified for the usability and evaluation phase of the research study. Five different construction companies from New Zealand participated in the field-testing of the mobile solution. We adopted a cognitive walkthrough method that simulated mobile use case scenarios so as to evaluate the 
usability of the mobile technology. This helped us in identifying specific on-site tasks for the participants to conduct and evaluate the effect of such construction processes using the mobile solution.

Figure 3 Field/Site usability and evaluation

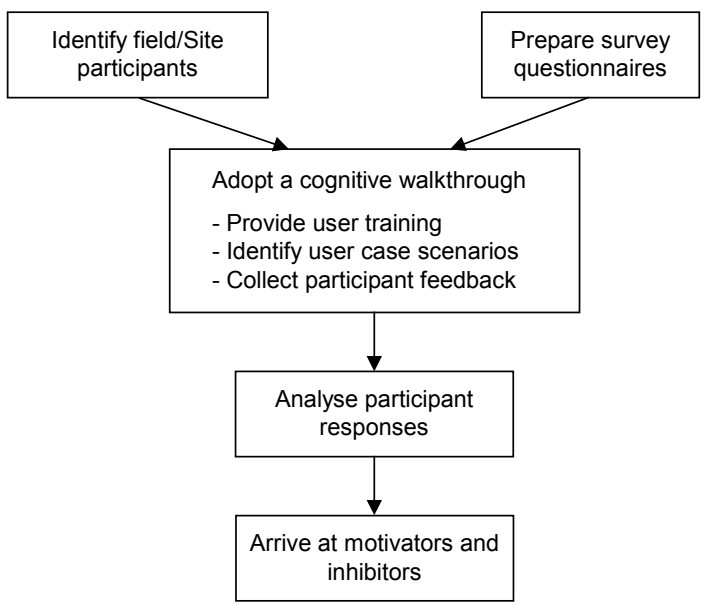

The next section provides the details of the findings at each phase of this research study.

\section{Research findings}

Construction projects usually operate on very tight time schedules with huge amounts of structured and un-structured information exchanges taking place among various parties. Some of the information communicated during construction activities consists of purchasing details of equipment and building material, budget and approvals, digital drawings and construction plans, e-mails and other business documents. A successful project completion requires a coordinated effort among construction workers, supervisors, architects, managers and even with external parties in the communication process. This research study examined the role of mobile technologies in improving the communication support for the construction industry so to increase efficiency and productivity in the construction process. The findings of the study are described in the subsections below.

\subsection{Findings from the exploratory phase}

The representatives from the various categories of the discussion group identified different problem domains that typically occurred in remote sites and debated on the sequence of events and modes of communication they would adopt to resolve such situations (Harrison et al., 2004). They also considered extraordinary processes that emanate whilst undertaking their work in the construction process and discussed how mobile communication technology could enhance the efficiency of the construction processes. These discussions were transcribed, verified and analysed using a qualitative-based, open coding methodology, wherein the topics of conversation were 
classified and patterns were identified within each event of the construction process workflow. From the analysis, the following common patterns and areas of application of mobile technologies were identified (a) collaboration with available technologies, (b) expert knowledge-based decision support, and (c) ad hoc access to information and other resources.

\subsubsection{Collaboration with available technologies}

Communication tools available onsite to a contractor varies depending on the size of the project (Reinhardt et al., 2002). Currently, the commonly used technology tools for remote collaboration are:

- facsimile

- mobile phone

- e-mail.

Digital drawings enabled complex three-dimensional problems and solutions to be communicated with minimal effort and maximum clarity. Consequently, the discussion group viewed the facsimile as a very important tool for remote collaboration.

Larger construction sites typically have a site office with computer, telephone and fax machine. Financially, the fax machine was not seen as prohibitive, but its need for a fixed landline is considered as a major constraint. E-mail is becoming an increasingly popular method of communication, especially amongst architects and managers. It is often used to describe progress and problems along with document attachments such as CAD files, scanned images and photographs. Currently, e-mail is used more widely in the design and management sectors where it is assisting organisations in partaking in projects based in another city or country (Yoong and Cleland, 2004).

\section{Existing constraint}

The ability to quickly reproduce documents for immediate distribution onsite was viewed as a current problem area, especially by architects who often had to convey the same three-dimensional information to numerous parties well after decisions had taken place. Typically this involved travel off site to utilise a computer, photocopier or fax machine and sometimes required to return back to the site for document distribution.

\section{Possible solution}

Mobile technology could address this constraint with regarding to collaborating with available technologies anywhere and anytime as it could possibly be designed to communicate with remote facsimile machines and tap on existing e-mail and internet computing facilities.

\subsubsection{Expert knowledge-based decision support}

In the construction industry, the project team members gain experience and knowledge in their specific functional area. The personnel, over a period of time, through various construction projects, develop a huge expert knowledge base from the practices and 
problem solving processes that take place in the sites. For example, the findings from the discussion group indicate that materials purchasing within New Zealand relies heavily on personal relationships and past experience. Often a contractor would have a specific point of contact within the supplier's organisation to place orders and queries. This streamlines the purchasing process and instils trust during urgent situations.

It was felt within the discussion group that having access to a broad knowledge base is often essential before a construction problem can be understood and resolved. When experienced construction personnel leave the organisation, so also their expert knowledge base. Most of the highly relevant information about the construction process typically remains locked within the personal experiences and knowledge of project members. Shortcomings within construction knowledge management associated to the accessibility and credibility of personal knowledge was identified in the research of Wetherhill et al. (2002).

\section{Existing constraint}

Mobile technologies, at present, do not accommodate personal relationships and expert knowledge to be stored as an expert knowledge base and most tools would struggle to be accepted within such an environment.

\section{Possible solution}

New mobile expert solutions could be developed to access the knowledge-base from remote servers.

\subsubsection{Ad hoc information needs}

The types of ad hoc information requirements in New Zealand construction industry were similar to those found in other overseas studies (Furusaka et al., 2000). An observation from the discussion group was that some of the most important information needed to resolve onsite problems was often not included in the formal documentation or not available when there are ad hoc requests.

Typically, generation of information occurred well after task completion and often in a different context (Scott and Assadi, 1997). The telephone help lines offered by suppliers and specifications providers were well respected by the discussion group as a good source meeting some ad hoc information needs. They were often used onsite when other information sources have not been useful.

\section{Existing constraint}

There is no formal manual/automated feedback system that compiles a set of ad hoc queries made in a project as document management tools were stored external to the construction site. A practical manifestation of this problem is in the correction of defects made during the project.

\section{Possible solution}

Mobile communication technology with 'push' and 'pull' information distribution model could be a possible solution to automatically connect to remote servers for catering to ad hoc information needs and feedback systems. 


\subsection{Findings from the design and development phase}

In the exploratory phase, it was observed that the mobile collaboration discussion group placed much importance on the facsimile as a collaboration tool and the inability to deploy such conventional devices onsite due to physical and practical constraints. Hence, in the design and development phase of this research work, the mobile solution development team considered the collaboration of mobile devices with the available technologies such as remote facsimile as a possible solution (as discussed in Section 4.1.1). The mobile facsimile solution based on third-generation mobile phone technology would be definitely desired by the New Zealand construction industry.

Hence, the development team suggested that a mobile facsimile system (called ClikiFax) would be an opportunity to improve productivity in the workflow processes at construction sites because, generally, it is not common to have conventional facsimile machines onsite due to physical and practical constraints (Wright et al., 2005). Apart from sending and receiving faxes using a mobile device, other useful features such as ability to draw some construction sketches, amending plans, and receive instant approvals at remote locations were considered as value-added features. To summarise, the following features and capabilities were implemented in the ClikiFax system:

- all in one mobile device (fax, phone, e-mail, internet, canvas for drawings, etc.)

- $\quad$ send/receive faxes between mobile devices and fax machines in a secured way

- edit and modify faxes/drawings on the spot and send them to other mobile devices/fax machines

- incoming notification of SMS messages to the mobile device when fax messages are received on the fax server

- national/international enabled fax transmissions

- authentication through login facility for site staff and administrators.

In the mobile solution development phase, a heuristic evaluation of the ClikiFax prototype was conducted internally. This was based on the ten usability factors (Nielsen, 1994) along with severity ratings (Nielsen, 1995) associated for each problem identified during the testing of the ClikiFax system. Findings from the heuristic evaluation were useful in refining the ClikiFax interface without providing any extra functionality. The various areas of improvement considered were, menu rationalisation, dialogue structure/programme navigation, viewing and navigating faxes, undo/error correction and login/logout connections (Wright et al., 2005). These enhancements were successfully implemented into the ClikiFax system and Figure 4 shows the mobile device with the sample screenshot of the system.

\subsection{Findings from the field usability and evaluation phase}

For new technologies to be used successfully they must be accepted by the organisations whose workers are expected to use them. Hence, the aim of the field usability and evaluation of the ClikiFax system was to understand how the system performed in the 'real-world' and to identify the challenges and benefits faced by the users while operating the system. The findings are summarised under three main influencing factors 
such as, task/job-related factors, behavioural factors and environmental factors. Summarised findings from the field evaluation of the ClikiFax system relating to these factors are presented here, indicating the attributing motivators and inhibitors (Venkatraman et al., 2007).

Figure 4 Mobile device and a screenshot of ClikiFax system (see online version for colours)

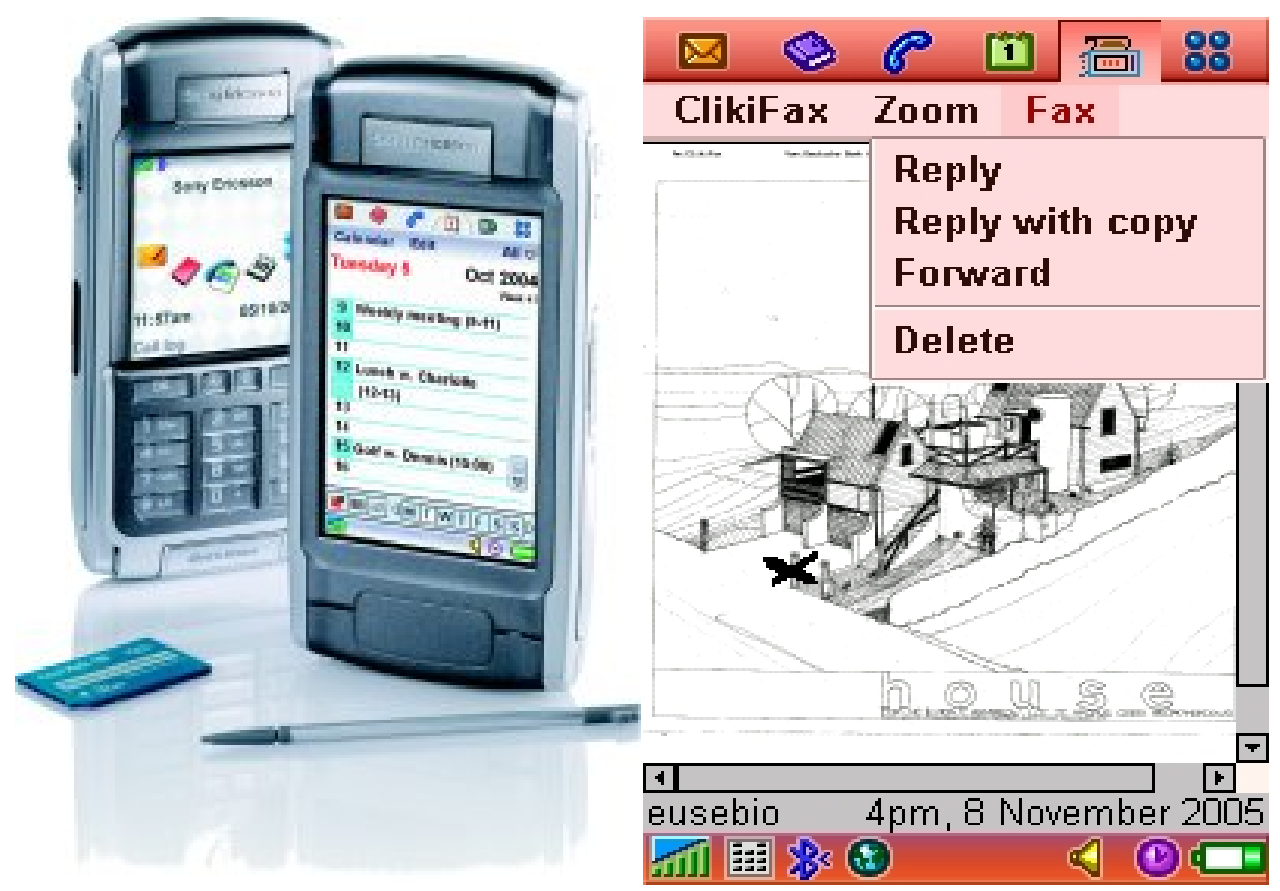

Source: Venkatraman et al. (2007)

\subsubsection{User task/job-related factors}

In order to understand the potential impact of the ClikiFax system with respect to users' job/task related matters, the main attributes such as, perceived usefulness, job fit, relative advantage and performance expectancy were investigated and the findings of the study are summarised as follows:

\section{Perceived usefulness}

All the participants perceived that the ClikiFax system could increase their overall productivity by allowing them to complete tasks such as sending a fax while working away from the office:

- Motivators - all the participants observed that the system could enhance the effectiveness on their jobs. Some of the main motivating factors are:

1 the ability to draw sketches and fax them immediately from remote sites

2 instant access to plans and other documents and the ability to solve problems that arise anywhere and anytime. 
- Inhibitors - overall, though the participants perceived the system as beneficial, some of the concerns were:

1 cost-benefit ratio of such a system for small businesses

2 the need to customise ClikiFax to become a useful tool for their businesses.

Job fit

According to majority of the participants, the ClikiFax system was considered to assist in time-critical tasks in their jobs as well as facilitating in their decision making:

- Motivators - construction site participants were required to receive, annotate, and forward faxes from remote sites as part of their job requirement and this matched well with the essential features provided by ClikiFax such as:

1 the ability to draw sketches and exchange confirmations

2 receive approvals from authorising parties such as project managers, local city councils and suppliers.

- Inhibitors - though majority of the participants perceived the system as a useful 'add-on' for their daily work, some drawbacks were:

1 they could not imagine integrating the system into their current business processes in its present form

2 they wanted the ClikiFax features to adapt to their job requirements automatically.

\section{Relative advantage}

In comparison with the existing communications methods, they felt that adopting ClikiFax could bring a relative advantage for their business, particularly because it allows them to access faxes from anywhere and anytime:

- Motivators - the participants considered the following as motivating factors with regard to relative advantage of ClikiFax as against their existing system:

1 good quality faxes and drawings could improve clarity and accuracy when communicating with other parties

2 maintenance of business documents and the organisation of business transactions would be better facilitated by the new system, saving time, energy, and space.

Overall ClikiFax was perceived as an enabler of relative advantage by providing an additional communication channel to the field workers.

\section{Performance expectancy}

Some participants perceived the system to be stable as they did not face any problems with the network or the device. However, many participants pointed out that the current server setup would be inappropriate for their jobs while some others faced some system errors during the trial. There were more expectations with regard to the performance of the system: 
- Inhibitors - the reliability, stability, and transaction speed of the ClikiFax system were not consistently high always as there were some network problems.

Improvements in these could lead to a better performance of ClikiFax.

\subsubsection{User behavioural factors}

The behavioural factors such as effort expectancy, attitude towards technology and anxiety were also evaluated and a summary of findings are given below:

\section{Effort expectancy}

- Motivators - all participants agreed that the initial walkthrough of the system helped them to learn the system much faster and some of the main motivators related to effort expectancy are:

1 user friendliness of the system

2 prior experience with mobile phones and PDAs was an influencing factor.

There was no major inhibiting factor as all the participants were using mobile phones for their daily work.

\section{Attitude towards using technology}

Most of the participants had a positive attitude and liked the idea of having fax capabilities on a mobile device. Many participants indicated an inclination for a high rate of usage of the system. However, some participants were observed to be more comfortable with the existing work practices. There were no significant motivators or inhibitors with regard to using mobile technology.

\section{Anxiety}

Some participants felt apprehensive about using the system at the beginning of the testing and felt unsure whether the system would really work and felt anxious about making mistakes that could have serious consequences in the system. However, after the initial walkthrough method adopted and subsequent self-exploration of the system they became more proficient. Hence any inhibiting factor related to anxiety could be addressed through appropriate training.

\subsubsection{User environmental factors}

The user's perceptions towards ClikiFax could be influenced by certain environmental factors such as social influence and facilitating conditions.

\section{Social influence}

All participants felt comfortable to use the system in public places or trains and they perceived the system just as an extension of a cell phone. They also felt comfortable using the technology while being with business clients. Hence social influence was definitely a motivating factor. 


\section{Facilitating conditions}

Most participants had the necessary resources such as, fax machine and server available to facilitate the testing of ClikiFax:

- Motivators - some of the motivating factors that relate to the facilitating conditions of ClikiFax are:

1 a walkthrough conducted during the initial testing period

2 a helpful user manual for participants to explore and test the system.

\section{Conclusions and future research}

It is observed that the workflow process adopted in construction industry relied much on strong personal relationships and the utilisation of a distributed knowledge network. Current form of collaboration tools such as the mobile phone, e-mail and fax are only enabling businesses to work less efficiently as there are redundancies and increased costs. This research unravelled the fact that technology-based collaboration tools, expert knowledge-based decision support systems and ad hoc information management tools were some of the avenues that could be adopted to improve the situation. We performed an exploratory study to identify the present constraints in construction industry and proposed one possible solution that uses mobile technology as a collaboration tool.

This paper described the development and evaluation of the proposed mobile collaboration tool, ClikiFax, with the potential to perform certain time-critical job functions at remote construction sites. The field testing and evaluation of ClikiFax conducted at five different construction companies in New Zealand indicated that the application could assist in business processes such as, dynamic changes to site drawings and approvals at remote construction sites. We considered three main influencing factors such as, task/job-related factors, behavioural factors and environmental factors while identifying the motivators and inhibitors of the ClikiFax system. Some of the improvements suggested were to enhance the system's integration and security features with the existing tools and standards.

The mobile facsimile collaboration tool, ClikiFax, that is based on a third-generation mobile phone technology would definitely benefit the New Zealand construction industry and it only serves as a starting point. In addition to this system, applications such as, 'Knowledge Finder' that could serve as an expert knowledge base tool and 'Versatile Catalogue' that could assist in ad hoc queries using document management techniques are some of the possibilities for future research.

\section{Acknowledgements}

This work was done as part of a funded research project, 'Mobile Collaboration with Construction Industry in New Zealand', undertaken by Victoria University of Wellington. The authors express their sincere thanks to the following research students and collaborators during the three phases of the project for their invaluable inputs. 
David Harrison, Rashina Hoda, Donald Gordon, Chris Andreae, Hartmut Hoehle, Roger Cliffe, Stuart Barnes, Robert Biddle, James Noble, Tim Wright and Eusebio Scornavacca.

\section{References}

Adriaanse, A.M., Voordijk, H. and Dewulf, G.P.M.R. (2004) 'Alignment between ICT and communication in construction projects', International Journal of Human Resources Development and Management, Vol. 4, No. 4, pp.346-357.

Alexander, J., Coble, R., Crawford, J., Drogemuller, R., Newton, P., Wilson, B. and Kwok-Keung, Y. (1998) 'Information and communication in construction: closing the loop', Digital Library of Construction Informatics and Information Technology in Civil Engineering and Construction, http://itc.scix.net/cgi-bin/works/Show?w78-1998-4.

Aziz, Z., Chimay, A., Darshan, R., Carrillo, P. and Bouchlaghem, D. (2004) 'Semantic web based services for intelligent mobile construction collaboration', Information Technology in Construction, Vol. 9, pp.367-379.

Bennett, D. and Vaidya, K. (2005) 'Meeting technology needs of enterprises for national competitiveness', Int. J. Technology Management, Vol. 32, Nos. 1-2, pp.112-153.

Chan, E.H.W. and Liu, C. (2007) 'Corporate portals as extranet support for the construction industry in Hong Kong and nearby regions of China', Information Technology in Construction, Vol. 12, pp.181-192.

Chien, H.J., Barthorpe, S. and Shih, J.K.C. (2003) 'The potential for Enterprise Resource Planning (ERP) in integrating the supply chain in the UK construction industry', Int. J. Internet and Enterprise Management, Vol. 1, No. 2, pp.185-209.

Chong, N.B., Uden, L. and Naaranoja, M. (2007) 'Knowledge management system for construction projects in Finland', Int. J. Knowledge Management Studies, Vol. 1, Nos. 3-4, pp.240-260.

Davis, F. (1986) A Technology Acceptance Model for Empirically Testing New End-User Information Systems: Theory and Results, Boston: Massachussetts Institute of Technology.

Equential (2004) 'Improving productivity and profit performance in construction \& field services: the value of mobile handheld computing solutions', Equential White Paper.

Furusaka, S., Kaneta, T., Ohta, M., Yamada, K. and Taira, T. (2000) 'Development \& management of a quality information system on construction site', Digital Library of Construction Informatics and Information Technology in Civil Engineering and Construction, http://itc.scix.net/cgi-bin/works/Show? w78:2000-385.

Gunasekaran, A. and Ngai, E.W.T. (2007) 'Managing digital enterprise', Int. J. Business Information Systems, Vol. 2, No. 3, pp.266-275.

Harrison, D., Barnes, S., Biddle, R., Yoong, P. and Noble, J. (2004) 'From hammer to handhelds: opportunities and barriers to mobile communication in the New Zealand building industry', Proceedings of the 4th International Postgraduate Research Conference in the Built and Human Environment, Salford, UK, 29 March-2 April.

Ismail, H., Reid, I., Arokiam, I. and Poolton, J. (2006) 'The significance of agile manufacturing techniques within SMEs in the construction industry', Int. J. Agile Systems and Management, Vol. 1, No. 3, pp.229-243.

Laborde, M. and Sanvido, V. (1994) 'Introducing new process technologies into construction companies', Journal of Construction Engineering Management, Vol. 120, No. 3, pp.488-508.

Lee, J.K. (2007) 'The technological experiences and catching-up path in the Korean mobile equipment industry', Int. J. Technology Management, Vol. 39, Nos. 3-4, pp.364-379.

Li, E.Y., Chen, J.S. and Huang, Y.H.A. (2006) 'Framework for investigating the impact of IT capability and organisational capability on firm performance in the late industrialising context', Int. J. Technology Management, Vol. 36, Nos. 1-3, pp.209-229. 
Magdic, A., Rebolj, D. and Cus-babic, N. (2002) 'Mobile computing in construction', Proceedings of Distributed Knowledge in Building, Denmark, 12-14 June.

Momaya, K. and Ajitabh, A. (2005) 'Technology management and competitiveness: is there any relationship?', Int. J. Technology Transfer and Commercialisation, Vol. 4, No. 4, pp.518-524.

Motawa, I.A., Price, A.D.F. and Sher, W. (2004) 'Modelling the implementation of technological innovations in construction', International Journal of Computer Applications in Technology, Vol. 20, Nos. 1-3, pp.78-89.

Nielsen, J. (1994) 'Heuristic evaluation', in J. Nielsen and R.L. Mack (Eds.) Usability Inspection Methods, New York: John Wiley \& Sons.

Nielsen, J. (1995) 'Severity ratings for usability problems', http://www.useit.com/papers/heuristic/ severityrating.html.

Nilsson, A. (2007) 'Managing IT implementation processes', Int. J. Business Information Systems, Vol. 2, No. 1, pp.41-57.

Pham, N. and Dawson, A. (2003) 'Data rich architectural environments', Proceedings of 20th Conference on Information Technology in Construction, Auckland, New Zealand, 23-25 April.

Plax, T.G. and Cecchi, L.F. (1989) 'Manager decisions based on communication facilitated in focus groups', Management Communication Quarterly, Vol. 2, No. 4, pp.511-535.

Raimonda, A. and Salvioni, G. (1998) 'A construction product browser', The Life-cycle of Construction IT Innovations, CiB W78, Stockholm.

Reinhardt, J., Akinci, B. and Garret, J., Jr. (2002) 'Using customized navigational models to deliver more efficient interaction with mobile computing devices on construction site', Proceedings of International Symposium on Automation and Robotics in Construction, Maryland, USA, 23-25 September.

Rogers, E.M. (1995) Diffusion of Innovations, New York: The Free Press.

Scott, S. and Assadi, S. (1997) 'Towards an electronic site diary', Information Technology Support for Construction Process Re-engineering, Cairns, Australia, 9-11 July.

Venkatraman, S. (2005) 'Mobile computing models - are they meeting the mobile computing challenges?', Association of Computing Machinery New Zealand, Vol. 1, No. 1, pp.3-12.

Venkatraman, S., Hoehle, H., Scornavacca, E. and Yoong, P. (2007) 'Developing and testing a mobile facsimile system: the case of ClikiFax', Proceedings of LA Global Mobility Roundtable, Los Angeles, USA, 1-2 June.

Vlachopoulou, M. and Manthou, V. (2006) 'Enterprise Resource Planning (ERP) in a construction company', Int. J. Business Information Systems, Vol. 1, No. 3, pp.339-351.

Wetherhill, M., Rezgui, Y. and Lima, C. (2002) 'Knowledge management and the construction industry: the e-Cognos project', Electronic Journal of Information Technology in Construction, Vol. 7, pp.183-196.

Wright, T., Yoong, P., Noble, J., Cliffe, R., Hoda, R., Gordon, D. and Andreae, C. (2005) 'Usability methods and mobile devices: an evaluation of MoFax', Proceedings of the 4th International Conference on Mobile and Ubiquitous Multimedia, Christchurch, New Zealand, 8-10 December.

Yoong, P. and Cleland, G. (2004) 'Exploring mobile internet meetings: a case study', Innovation: Management, Policy and Practice, Vol. 6, No. 1, pp.106-114.

Yoong, P. and Huff, S. (2007) Managing IT Professionals in the Internet Age, USA: Idea Group. 